\title{
A História da Polop e seu enfrentamento a Ditadura Militar
}

CAIO LIMA DE OLIVEIRA CARVALHO

Bolsista PROBIC/UEFS, Graduando em História, Universidade Estadual de Feira de Santana, e-mail: carvalhocaio01@gmail.com

Eurelino Teixeira Coelho Neto, Departamento de Ciências Humanas e Filosofia, Universidade Estadual de Feira de

Santana, e-mail: eurecoelho@uefs.br

PALAVRAS-CHAVE: Esquerda, Polop, Ditadura.

\section{INTRODUÇÃOO}

O I congresso da Organização Revolucionária Marxista - Política Operária (ORM-PO) ou como ficou mais conhecida, Polop, ocorreu em 1961 e marca o início da organização. Sua fundação foi iniciativa de um grupo do Rio de Janeiro que desde 1959 editava um boletim quinzenal chamado Política Operárial A organização tinha como característica diferencial a leitura de capitalismo brasileiro, e no seu I congresso formulou propostas em contraposição ao que consideravam uma alternativa reformista contida no conjunto das concepções do Partido Comunista Brasileiro (PCB), principal representação comunista na época ${ }^{2}$. O congresso teve participação de uma diversidade de grupos e estados do Brasil, entre os presentes estavam: Mocidade Trabalhista de Minas Gerais, a Juventude Socialista e também a Liga Socialista Independente. Dentre os estados presentes com grupos ou militantes sozinhos, estavam Bahia, Rio de Janeiro, Minas Gerais e São Paulo. Eric Sachs, dirigente da POLOP, sintetiza a orientação política da organização numa frase que reapareceria em vários documentos posteriores "qualquer futura revolução no Brasil será socialista ou não será revolução."3 O objetivo dessa pesquisa, é mapear a orientação da organização sobre foco e também sua participação na Guerrilha de Caparaó

\section{MATERIAL E MÉTODOS OU METODOLOGIA (ou equivalente)}

A pesquisa baseia-se em análise documental e dispõe, para tanto, da coleção em poder do LABELU. Este corpus compõe-se de aproximadamente 1500 peças organizadas provisoriamente em cinco categorias, sendo essas: Teses Nacionais; Teses Gerais (internacionais); Periódicos (Política Operária, Marxismo Militante, Brasil Socialista, Teoria e Prática); Documentos de circulação interna (Boletins nacionais, Tribuna de debates, Circulares, Cadernos da Esquerda Revolucionária, Curso Básico); Documentos internacionais (vínculos internacionais da PO).

\footnotetext{
${ }^{1}$ OLIVEIRA, Joelma Alves de. POLOP AS ORIGENS, A COESÃO E A CISÃO DE UMA ORGANIZAÇÃO MARXISTA (1961-1967). 2007. Dissertação - Curso de Sociologia, Universidade Estadual Paulista, Araraquara, 2007. Cap. 5. Pág. 52

2 Ibid. Pág. 52

${ }^{3}$ Op. cit.
} 


\title{
RESULTADOS E/OU DISCUSSÃO (ou Análise e discussão dos resultados)
}

Antes de discutimos a posição da organização de como enfrentar o regime militar de 1964, é importante situar qual o caráter que organização via no regime. Tema que foi discutido pelo historiador Eurelino Coelho no artigo A Polop, O Golpe e a Ditadura. Em sua pesquisa, o historiador conclui que a organização, acreditava que a Ditadura militar, é também uma forma de Estado Burguês, só que pela conjuntura a Burguesia acabou precisando usar a ditadura não mais velada e escondida através de eleições, mas sim, uma ditadura aberta.

Coerente com sua análise de Estado, a Polop demarcou o enfrentamento ao regime como "luta contra o Estado burguês em uma de suas formas, ou seja, a tática (política para enfrentar a ditadura) se demarcava no território político delimitado pela estratégia da revolução socialista". 4

Algumas organizações como a Aliança Libertadora Nacional (ALN) dirigida por Carlos Marighella e MR8 são conhecidas por terem aderido à guerrilha e à luta armada, com influências que chegaram a todas organizações de esquerda. Sobre à guerrilha, Coelho nos mostra como o posicionamento da Polop sofreu algumas mudanças com o passar dos anos:

\begin{abstract}
Num primeiro período, compreendido entre o pós-golpe e os últimos anos da década de 60, o foco guerrilheiro é considerado necessário e a ele é dedicada atenção frequente nos documentos da organização. Em janeiro de 1965 a prioridade era superar a dispersão gerada pelo golpe, que atingiu a POLOP com prisões, inclusive de dirigentes, logo nos primeiros meses. Com o objetivo de preparar a organização para atuar sob as novas condições impostas pela ditadura a direção emite uma "Orientação interna" em janeiro de 1965, e nela a guerrilha já é abordada. ${ }^{5}$
\end{abstract}

Mas a organização ressalva que não é somente pegar em armas e tentar derrubar o regime:

Nada de abandonar a prioridade do trabalho político junto à classe operária, questão de honra reafirmada em todos os momentos da trajetória da organização. $O$

\footnotetext{
${ }^{4}$ COELHO, Eurelino. Dissonâncias à esquerda: a POLOP, o golpe e a ditadura militar. In: MATTOS, Marcelo Badaró e VEGS, Rubén (orgs.) Trabalhadores e Ditaduras: Brasil, Espanha e Portugal. Rio de Janeiro, Consequência, 2014. Pág. 10.

${ }^{5}$ Op. Cit.
} 
terreno essencial em que esse trabalho teria de ser feito era, portanto, a classe operária: conselhos e comitês de fábricas, construídos no espaço deixado pelo desmantelamento das cúpulas sindicais reformistas, seriam a base da criação de núcleos revolucionários. ${ }^{6}$

Desta forma, a Polop não vê a guerrilha isolada das lutas dos trabalhadores, e sim como ferramenta para "desintegrar e desgastar o instrumento principal da opressão - as forças armadas" e também "armar os trabalhadores"7, tarefas que seriam cumpridas pela guerra de guerrilhas.

Alguns anos após a ditadura o ex-militante da Polop, Muniz Bandeira, deu uma entrevista falando sobre os primeiros após o golpe: "com o golpe de 64 nós decidimos deflagrar a guerrilha de Caparaó para insuflar as Forças Armadas”, e é provável que realmente esse seria o objetivo da organização, mas, a inteligência da marinha (CENIMAR), descobriu os aparelhos da organização em Copacabana e prendeu vários militantes e militares. A Polop tinha uma significativa inserção junto a setores militares, principalmente marinheiros, e acreditava que se parte dos militares se rebelam-se, poderiam começar levantes pelo Brasil contra o regime. Se esses militantes pudessem começar uma guerrilha, poderia ser o começo dos levantes. Em Copacabana também foi apreendido materiais como armas e suprimentos, que mostram preparação para uma guerrilha.

O jornalista José Caldas da Costa, organizou o livro: Caparaó: a primeira guerrilha contra a Ditadura ${ }^{8}$. A intenção do autor é reconstruir o que foi a guerrilha, através da visão dos militantes que participaram e para isso foram necessários 10 anos recolhendo materiais, principalmente oriundo de fontes orais. José da Costa não chegou a entrevistar militantes da Polop, afinal, eles não chegaram a participar efetivamente, mas na entrevista dos que realmente participaram, podemos ver a presença da organização na preparação para a guerrilha. Avelino Capitani, ex-marinheiro e um dos participantes da Guerrilha do Caparaó, contou que a "com seus amigos da diretoria de associação dos marinheiros, tentava organizar a categoria, mas sem opção, juntou-se à Polop, que estava com a guerrilha - de Caparaó - na cabeça". Mas, "o CENIMAR estourou, simultaneamente, cinco aparelhos da organização clandestina em Copacabana, na zona norte e em Nova Iguaçu, e prendeu cerca de setenta pessoas. "10 Avelino não foi

\footnotetext{
${ }^{6}$ Ibid. Pág. 11.

${ }^{7}$ Op. Cit.

${ }^{8}$ Lançado pela Editora BoiTempo. 10 edição 2007.

${ }^{9}$ Retirado de Caparaó: a primeira guerrilha contra a Ditadura. José Caldas da Costa. 2007, Pag. 109.

${ }^{10}$ Op. Cit.
} 
preso na ocasião, por não estar no apartamento no momento da chegada dos militares. Outro militante que participou da guerrilha, nos fornece mais informações da participação da Polop em Caparaó. Jelcy Rodrigues Côrrea, conta que

$$
\begin{aligned}
& \text { "à Organização Revolucionária Marxista Política } \\
& \text { Operária (Polop) fizera o estudo na serra de Caparaó } \\
& \text { antes mesmo de os ex-sargentos voltarem do Uruguai } \\
& \text { para instalar ali um foco guerrilheiro. Mas, quando } \\
& \text { Amadeu retornou ao Rio para tocar o projeto, a Polop já } \\
& \text { havia caído nas mãos da repressão e estava sem } \\
& \text { condições de realizar qualquer ação." }{ }^{11}
\end{aligned}
$$

Diante das fontes analisadas, conseguimos concluir que realmente era intenção da organização realizar um foco guerrilheiro em Caparaó, mas a ação do CENIMAR foi mais rápida que a Polop e a organização acabou não conseguindo realizar seu plano. O impacto que a ação do CENIMAR realiza na organização é muito grande, a mesma passa a priorizar a proteção dos militantes para que mais não sejam presos, e somente consegue voltar a ação política mais estruturada e ampla no ano de 1965. Mas isso já é outra história...

\section{CONSIDERAÇÕES FINAIS (ou Conclusão)}

Concluímos que a Polop, buscou resistir e se movimentar após o golpe de 1964, nos planos da organização tinha a realização da Guerrilha de Caparaó como vimos, mas que acabou não acontecendo com os militantes da organização. A organização também no período estudado, mostrou um grande esforço em aplicar a teoria marxista no Brasil e buscar novas alternativas para a revolução brasileira.

\section{REFERÊNCIAS}

. OLIVEIRA, Joelma Alves de. POLOP AS ORIGENS, A COESÃO E A CISÃO DE UMA ORGANIZAÇÃO MARXISTA (1961-1967). 2007. Dissertação - Curso de Sociologia, Universidade Estadual Paulista, Araraquara, 2007.

COELHO, Eurelino. Dissonâncias à esquerda: a POLOP, o golpe e a ditadura militar. In: MATTOS, Marcelo Badaró e VEGS, Rubén (orgs.) Trabalhadores e Ditaduras: Brasil, Espanha e Portugal. Rio de Janeiro, Consequência, 2014. Pág. 10.

COSTA, José Calda da. Caparaó: a primeira guerrilha contra a Ditadura. 2007.

\footnotetext{
${ }^{11}$ Op. Cit.
} 